\title{
The relationship between income inequality and obesity in all 47 prefectures of Japan: Ecological study*
}

\author{
Akihiko Katayama, Nobuyuki Miyatake ${ }^{\#}$, Kanae Oda, Takeshi Saito, Shoko Murakami, \\ Noriko Sakano
}

Department of Hygiene, Faculty of Medicine, Kagawa University, Miki, Kagawa, Japan

Email: ${ }^{*}$ miyarin@med.kagawa-u.ac.jp

Received 28 December 2012; revised 28 January 2013; accepted 7 February 2013

\begin{abstract}
The link between income inequality and obesity in Japan was evaluated. Income inequality of all 47 prefectures of Japan as expressed by Gini coefficient was obtained from National Statistics Center, Japan. The rate of obesity (\%) was also obtained from National Nutrition Survey, Japan. The effect of income inequality on obesity was evaluated by ecological study. Income inequality as expressed by Gini coefficient was $0.31 \pm 0.01$ and the rate of obesity was $31.6 \% \pm$ $5.6 \%$. Gini coefficient was significantly and positively correlated with the rate of obesity $(r=0.490, p=$ $0.0005)$. Income inequality was might be associated with the rate of obesity in Japan.
\end{abstract}

Keywords: Income Inequality; Gini Coefficient; Obesity; Ecological Study; Japan

\section{INTRODUCTION}

Obesity and its related diseases has become serious problem and public health challenge in Japan. For example, $30.3 \%$ in men and $21.5 \%$ in women were reported to be obesity (Body mass index $\geq 25 \mathrm{~kg} / \mathrm{m}^{2}$ ) by the National Nutrition Survey in Japan [1]. Therefore, proper management of obesity is urgently required. It is well known that obesity and its related conditions are closely related to lifestyle such as exercise habits, diets habits, drinking habits and cigarette smoking [2-4]. However, the link between the income inequality and obesity still remains to be investigated in Japan.

In this study, we investigated the effect of income inequality on obesity in all 47 prefectures of Japan by ecological study.

${ }^{*}$ The authors have no conflict of interest with the material presented in this paper.

${ }^{\#}$ Corresponding author.

\section{METHODS}

\subsection{Income Inequality}

Income inequality as expressed by Gini coefficient (2009) was obtained by National Statistics Center, Japan [5]. The Gini coefficient was used to measure income differentials. It theoretically ranges from 0.0 (perfect equality) to 1.0 (absolute inequality). Mathematically, the Gini coefficient is equivalent to half the average absolute difference between the incomes of any two households randomly sampled for a population, and then normalized to the mean [6].

\subsection{The Rate of Obesity}

The rate of obesity in men (\%) in all 47 prefectures of Japan was obtained from the National Nutrition Survey by Ministry of Health, Labour and Welfare, Japan [7]. The rate was obesity was obtained from 2006 to 2010, and was adjusted for age.

\subsection{Statistical Analysis}

A simple correlation analysis was used to test the significance of the linear relationship among continuous variables: $\mathrm{p}<0.05$ was considered to be statistically significant.

\section{RESULTS}

Gini coefficient was $0.31 \pm 0.01$, and Okinawa prefecture, which is located most southern part of Japan was the highest (0.339) and Kyoto prefecture was the lowest $(0.274)$. The rate of obesity in men was $31.6 \% \pm 5.6 \%$, and Okinawa prefecture was the highest $(45.2 \%)$ and Yamaguchi prefecture was the lowest (22.1\%).

Income inequality expressed as Gini coefficient were significantly and positively correlated with the rate of obesity in men (\%) (Figure 1). 


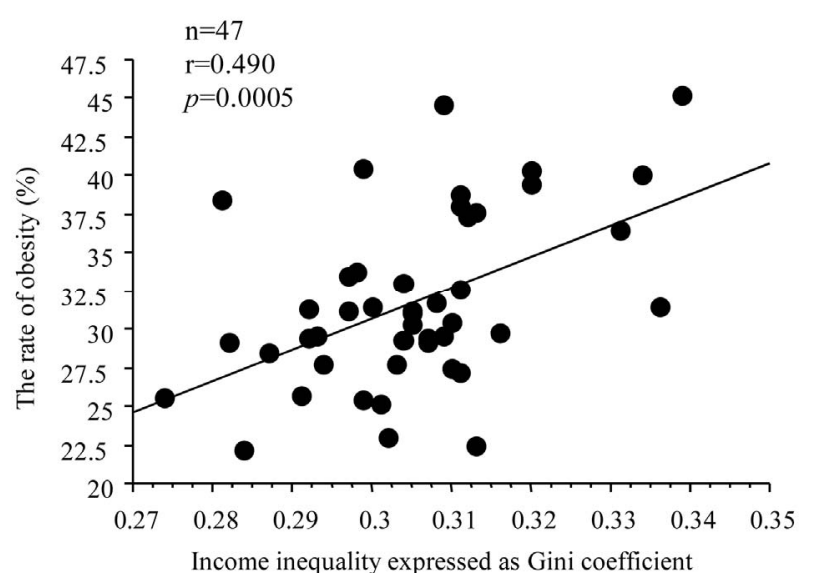

Figure 1. Simple correlation analysis between income inequality expressed as Gini coefficient and the rate of obesity (\%) in all 47 prefectures of Japan.

\section{DISCUSSION}

We evaluated the income inequality expressed as Gini coefficient and obesity in all 47 prefectures of Japan by ecological study. Positive correlation between income inequality and obesity was noted in this study.

Chiavegatto et al. reported the difference between high and low income inequality areas was statistically significant for homicide, ischemic heat disease, HIV/AIDS and respiratory disease in Brazil [6]. Robert et al. also showed that community income inequality had independent positive association with body mass index of black adults in the US [8]. In Japan, blue collar occupation and middle household income were found to be associated with high prevalence of diabetes mellitus [9]. Hasegawa also reported that the relationship between income inequality expressed as Gini coefficient (2004) and the rate of obesity (2008), and the correlation coefficients were 0.291 in men and 0.356 in women [10]. In this study, income inequality expressed as Gini coefficient was closely related to the rate of obesity (men) in all 47 prefectures of Japan. It is interesting and noteworthy that the correlation coefficient is higher in this study than that in previous report. Gini coefficient has increased by the repot of Ministry of Health, Labour and Welfare, Japan [11]. In addition, the rate of obesity in this study was averaged for 5 years and adjusted for age. Therefore, the correlation coefficient between Gini coefficient and the rate of obesity was higher in this study than that in previous report. Income inequality may induce the difference of the lifestyle such as exercise, diet and cigarette smoking. In fact, by National Nutrition Survey in Japan, the level of vegetable consumption in men with low income was lower than that in men with high income [1]. Fruit and meat consumption was lower in subjects with low income than that in subjects with high income in both genders [1]. Taken together, correlation coefficient may increase in fu- ture.

Potential limitations still remain in this study. First, we used an ecological study. The link between income inequality expressed as Gini coefficient and the rate of obesity, which was noted in this study, may not apply for the link among individuals. Second, we could not obtain the data of the rate of obesity in women. The third, other confounding factors i.e. education, occupation, lifestyle and locations of prefectures were not evaluated in this study, therefore, we could not evaluate the link between income inequality and obesity as accurately as we wished. Further ongoing investigations are urgently required to prove such a link.

\section{REFERENCES}

[1] Ministry of Health, Labor and Welfare, Japan (2011) The national nutrition survey, Japan.

http://www.mhlw.go.jp/stf/houdou/2r9852000002q1st-att 2r9852000002q1wo.pdf

[2] Miyatake, N., Saito, T., Wada, J., Miyachi, M., Tabata, I., Matsumoto, S., Nishikawa, H., Makino, H. and Numata, T. (2007) Comparison of ventilatory threshold between subjects with and without metabolic syndrome. Diabetes Research and Clinical Practice, 77, 314-319. doi:10.1016/i.diabres.2006.11.008

[3] Endo, M., Nakanishi, Y. and Miyatake, N. (2011) The relation between insulin resistance and lifestyle in Japanese female university students. Acta Medica Okayama, 65, 199-204.

[4] Miyatake, N., Wada, J., Kawasaki, Y., Nishii, K., Makino, H. and Numata, T. (2006) Relationship between metabolic syndrome and cigarette smoking in the Japanese population. Internal Medicine, 45, 1039-1043. doi:10.2169/internalmedicine.45.1850

[5] National Statistics Center (2011) Income differentials in 47 prefectures of Japan.

http://www.e-stat.go.jp/SG1/estat/List.do?bid=00000103 $4909 \&$ cycode $=0$

[6] Chiavegatto Filho, A.D., Gotlieb, S.L. and Kawachi, I. (2012) Cause-specific mortality and income inequality in Sao Paulo, Brazil. Revista de Saude Publica, 46, 712-718.

[7] Ministry of Health, Labour and Welfare, Japan (2010) The national nutrition survey.

http://www.mhlw.go.jp/bunya/kenkou/eiyou/dl/h22-houk oku-11.pdf

[8] Robert, S.A. and Reither, E.N. (2004) A multilevel analysis of race, community disadvantage, and body mass index among adults in the US. Social Science \& Medicine, 59, 2421-2434. doi:10.1016/j.socscimed.2004.03.034

[9] Hayashino, Y., Yamazaki, S., Nakayama, T., Sokejima, S. and Fukuhara, S. (2010) The association between socioeconomic status and prevalence of diabetes in rural Japan. Archieves of Environmental \& Occupational Health, 65, 224-229. doi:10.1080/19338244.2010.486423

[10] Hasegawa, T. (2011) The relationship between the rate of 
obesity and socio-economic differentials in Japan. Journal of Health and Welfare Statistics, 58, 18-22.

[11] Ministry of Health, Labor and Welfare, Japan (2008) Changes in Gini coefficient of income in Japan. http://www.mhlw.go.jp/stf/houdou/2r9852000000nmrn-at

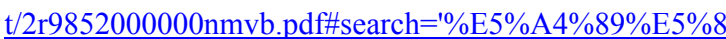
C\%96+\%Е6\%89\%80\%E5\%BE\%97+\%E3\%82\%B8\%E3 $\% 83 \% 8 \mathrm{~B} \% \mathrm{E} 4 \% \mathrm{BF} \% 82 \% \mathrm{E} 6 \% 95 \% \mathrm{~B} 0$ 